\title{
Customised symphysio fundal height charts
}

\author{
K H B Shamawarna1', I M R Goonewardene', Y A G Perera ${ }^{3}$
}

(Index words: customised symphysio fundal height charts)

\begin{abstract}
Objectives To evaluate the feasibility, applicability and the value of customised symphysio fundal height (SFH) charts developed for women of Indian origin in the United Kingdom (UK: CSFH - In chart) and women of African origin in the UK (CSFH - Af chart) in detecting fetal growth restriction and predicting low birth weight (LBW) of the neonate in a Lankan population, and to compare these results with the results obtained from the SFH chart currently used in Sri Lanka (FHB chart) and another SFH chart which uses a range of plus or minus $2-3 \mathrm{~cm}$ of the value of the gestational age in weeks as the reference range ( $G A \pm 2$ to $3 \mathrm{~cm}$ chart).

Methods Pregnant women $(n=416)$ with confirmed periods of gestation (POG) of $<22$ weeks and having a singleton fetus and with no obstetric complications, had their age, parity, POG and Body Mass Index (BMI) documented. Their SFH were measured at four weekly, fortnightly and weekly intervals between $20-28,28-36$ and $37-41$ weeks respectively and plotted on the CSFH - In chart, CSFH - Af chart, FHB chart and the GA \pm 2 to 3 $\mathrm{cm}$ chart. The gestational age at delivery and the birth weight were recorded. Pre term deliveries were excluded leaving 401 participants for analysis.
\end{abstract}

Results There were 164 (39.4\%) primigravidae, 76 (18.9 $\%)$ had low BMI and 71 (17.7\%) had a high BMI. Maternal $\mathrm{BMI}$ at booking was positively correlated to the birth weight of the baby but not the parity. In detecting LBW at term, the CSFH - In chart had the best sensitivity, specificity, positive predictive value, negative predictive value, and the likelihood ratios. Of the two non customised charts the $\mathrm{GA} \pm 2$ to $3 \mathrm{~cm}$ chart was better than the FHB chart.

Conclusions Until a customised SFH chart is developed for Sri Lanka, the CSFH - In chart or the GA \pm 2 to $3 \mathrm{~cm}$ chart should be used for antenatal monitoring of fetal growth.

Ceylon Medical Journal 2012; 57: 159-165

\section{Introduction}

A fetus which is below the 10th centile for its expected gestational age specific birth weight is generally considered to be small for gestational age (SGA) [1]. However, it is important to differentiate between a healthy constitutionally small fetus with no associated adverse outcomes from a fetus that has pathological intra uterine fetal growth restriction (FGR) with associated perinatal and long term adverse outcomes [1,2]. The measurement of the symphysio fundal height (SFH) has been shown to have specificities of up to $94 \%$ in detecting a SGA fetus, but the sensitivities reported vary from $84 \%$ to $27 \%[3,4]$.

The low sensitivity, high false positive rates, significant intra and inter observer variations make SFH per se an unreliable index in detecting SGA [4,5]. Although the mean value of SFH in $\mathrm{cm}$ plus or minus $2 \mathrm{~cm}$ in Caucasian populations has been found to approximate the gestational age in weeks between 20 - 36 weeks of gestation very often it is approx $2 \mathrm{~cm}$ less than the value in weeks [6]. Furthermore between 36 - 40 weeks the range could be as large as plus or minus $3 \mathrm{~cm}$ and at 40 weeks the range could be as large as plus or minus $4 \mathrm{~cm}$ [6]. The interpretation of a single SFH measurement in centimetres to be corresponding to the gestational age in weeks (ie. a point to point conversion) is not logical. Serial ultrasound measurement of growth velocity using fetal abdominal circumference and estimated fetal weight have been shown to be the best indices to predict FGR [7]. Therefore serial SFH measurements plotted on a reference chart may be a useful screening tool to detect FGR $[8,9]$.

SFH measurements have been used for more than four decades and its limitations, especially on account of the wide variation in body stature and lengths of women's abdomens, have been appreciated from its inception [10]. The main non pathological factors which affect the birth weights are gestational age, maternal height, maternal weight at booking, parity and ethnic group [11].

Maternal age appears to have no significant effect when parity is controlled for [11]. Paternal height, unless extreme, appears to have a relatively minor effect. Using a data set of around 40,000 ultrasound dated pregnancies and adjusting for the main non pathological factors which affect fetal growth, a Term Optimal Weight (TOW) which is the weight the baby is predicted to achieve in the absence of pathological influences has been calculated in Nottingham UK, Australia, New Zealand and the United States of America [11-14].

\footnotetext{
${ }^{1}$ Obstetrics and Gynaecology Unit, Teaching Hospital, Mahamodara, Galle, ${ }^{2}$ Department of Obstetrics and Gynaecology, University of Ruhuna, Faculty of Medicine, Galle, Sri Lanka.
}

Correspondence: IMRG, e-mail: <malikg@eureka.lk>. Received 18 May and revised version accepted 9 August 2012. Competing interests: none declared. 
Using the TOW, a proportionality curve can be drawn to demonstrate how this weight is expected to be reached in a normal pregnancy. Then, individually adjusted (customised) Gestation Related Optimum Weight (GROW) charts can be obtained to plot the serial SFH measurements and monitor fetal growth [14]. These customised SFH charts have been found to be better in antenatal fetal monitoring and detecting SGA fetuses $[24,25]$. Therefore serial measurement of SFH plotted on customised SFH charts has been recommended $[1,15,16]$. SFH charts developed in the UK, Australia and New Zealand, and customised according to ethnicity, parity and BMI are available as the computer software GROW which can be downloaded free of charge for personal or institutional use [17]. These charts show the Term Optimal Weight calculated for 280 days and they are individually adjusted (customised according to ethnicity, parity and BMI). These charts include proportional growth curves together with the 10th and 90th centile lines showing how this weight is expected to be reached during a normal pregnancy. Longitudinally plotting the SFH on these charts during the pregnancy enables the monitoring of fetal growth. The objective of the current study was to compare the following SFH charts in the detection of low birth weight babies $(\mathrm{LBW}=<2.5 \mathrm{~kg}$ ) at term ( $>37$ weeks gestation):

1. Customised SFH Charts developed for women of Indian origin in the UK (CSFH - In: Figures 1, 2 and 3)

2. Customised SFH Charts developed for women of African origin in the UK (CSFH - Af: Figure 4)

3. SFH Chart using the gestational age plus or minus 2 $\mathrm{cm}$ from 20 - 36 weeks and gestational age plus or minus $3 \mathrm{~cm}$ from 36 - 40 weeks as the reference range $(\mathrm{GA} \pm 2$ to $3 \mathrm{~cm}$ Chart: Figure 5)

4. The SFH Chart included in the Lankan Pregnancy Record Card (FHB Chart: Figures 6)

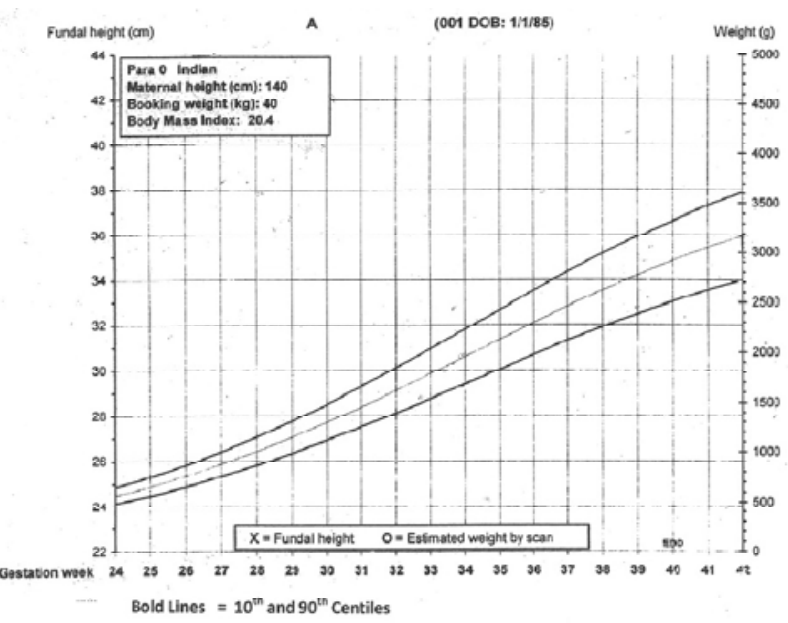

Figure 1. Customised antenatal growth chart.

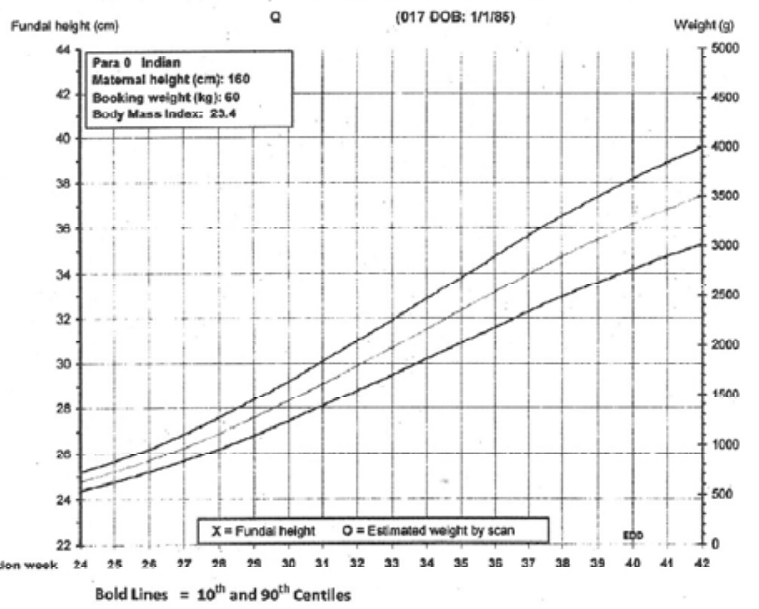

Figure 2. Customised antenatal growth chart.

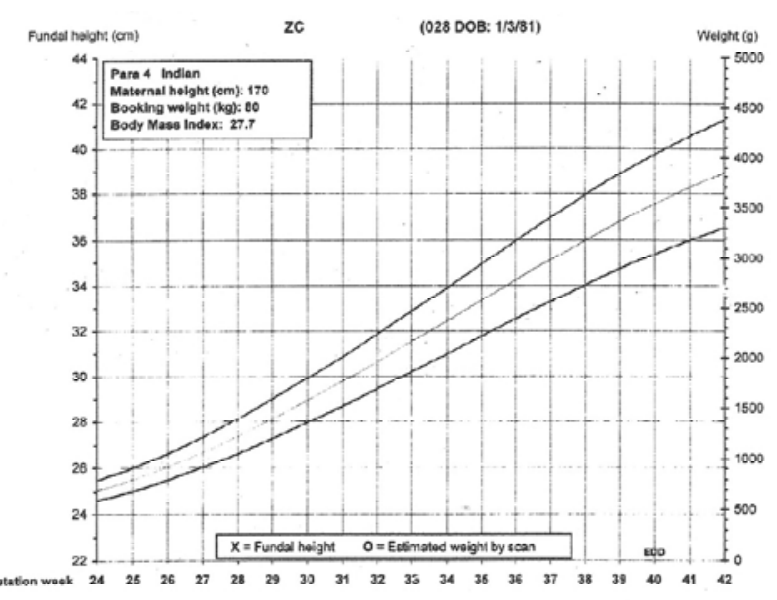

Bold Lines $=10^{\text {th }}$ and $90^{\text {th }}$ Centiles

Figure 3. Customised antenatal growth chart.

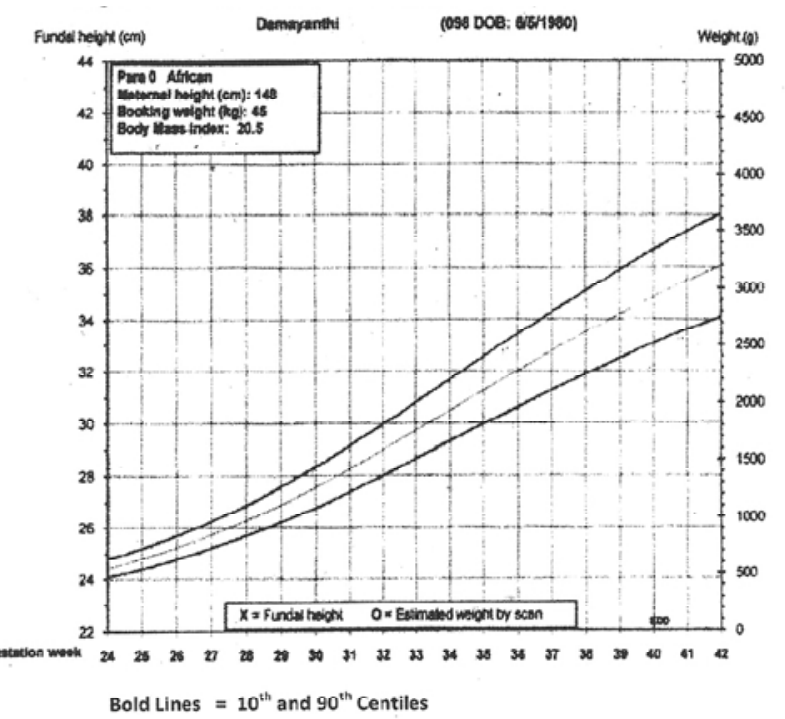

Figure 4. Customised antenatal growth chart. 


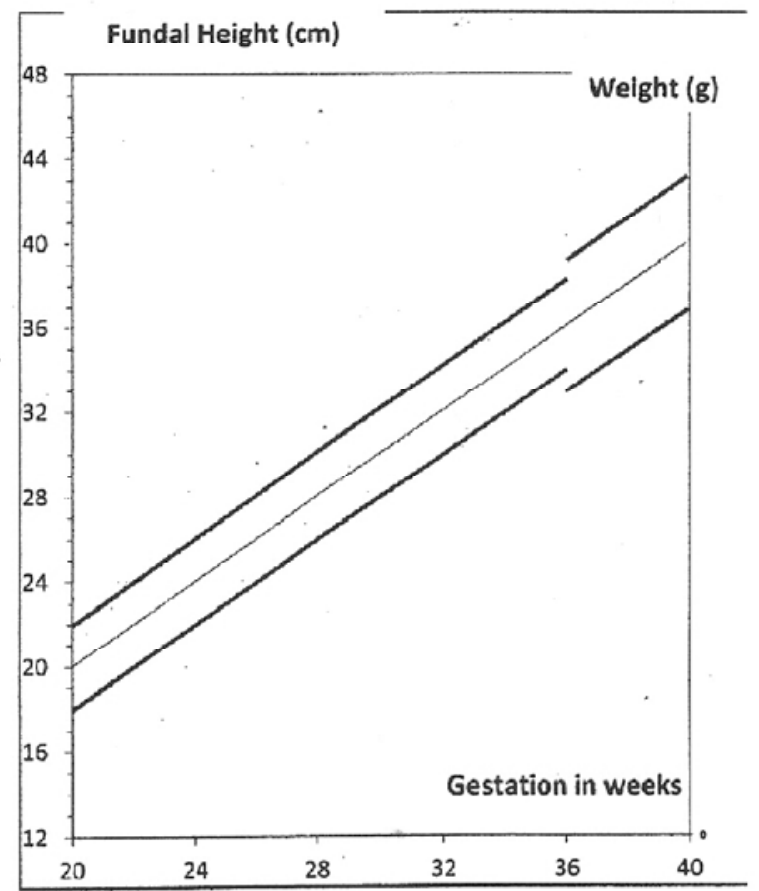

Figure 5. gestational age \pm 2 to $3 \mathrm{~cm}$ SFH chart.

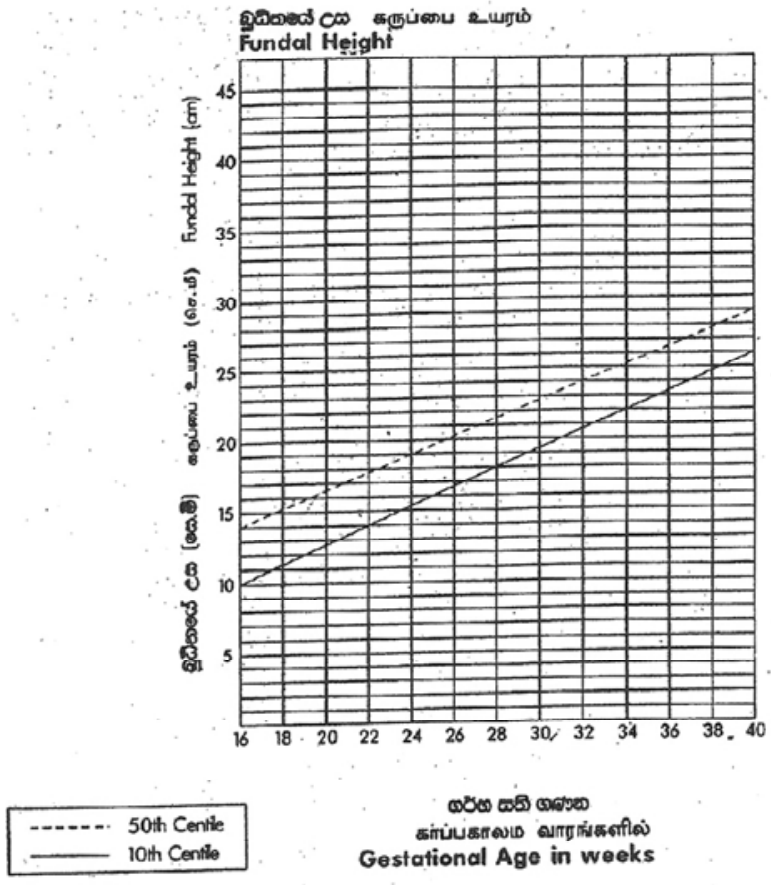

Figure 6. FHB chart

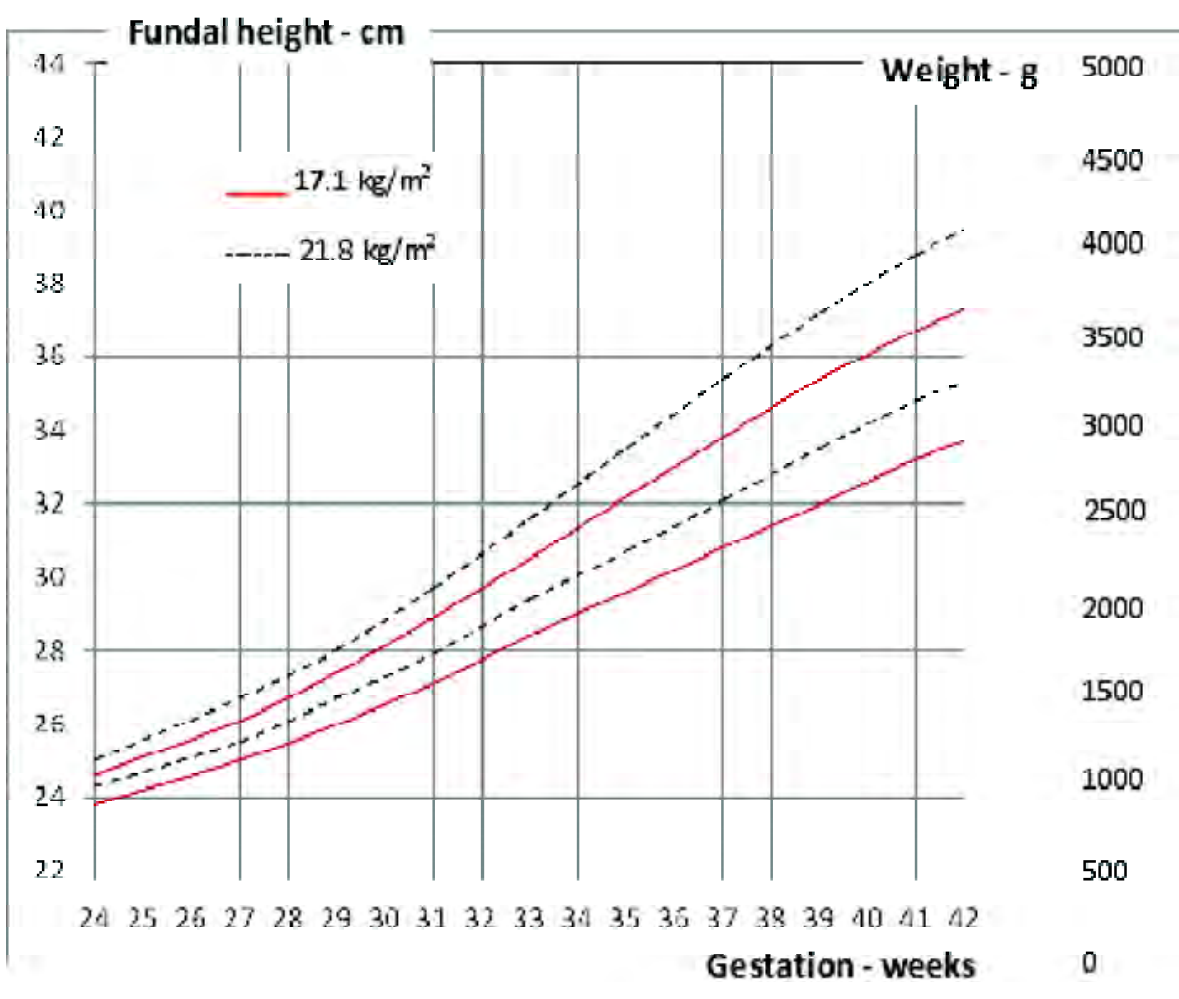

Figure 7. Symphysio fundal height chart - customized according to body mass index

Red $=10$ th and 90th centiles of symphysio fundal height chart customised according to a body mass index of $17.1 \mathrm{~kg} / \mathrm{m}^{2}$

Black $=10$ th and 90 th centiles of symphysio fundal height chart customised according to a body mass index of $21.8 \mathrm{~kg} / \mathrm{m}^{2}$ 
The mean birth weight of a Lankan newborn in the Galle District is estimated to be approx. $2.9 \mathrm{~kg}$ and $20.8 \%$ of babies are considered to be of low birth weight defined as $<2.5 \mathrm{~kg}$ [26]. In the CSFH - In chart the 50th centile of the birth weight of a baby born at 40 weeks to a primigravida having a height of $140 \mathrm{~cm}$, booking weight $40 \mathrm{~kg}$ and BMI of $20.4 \mathrm{~kg} / \mathrm{m}^{2}$ is approximately $2.9 \mathrm{~kg}$ and in the CSFH - Af chart the 50th centile of the birth weight of a baby born at 40 weeks to a primigravida having a height of $148 \mathrm{~cm}$, booking weight $45 \mathrm{~kg}$ and BMI of $20.5 \mathrm{~kg} / \mathrm{m}^{2}$ is approximately $2.9 \mathrm{~kg}$ [17]. This was the rationale for including the $\mathrm{CSFH}$ - In and the CSFH - Af customised SFH charts in the current study.

\section{Methods}

Approval was obtained from the Ethical Review Committee of the Faculty of Medicine, University of Ruhuna and informed written consent was obtained from all the participants recruited for the study. The normal range of BMI is considered to be $18.5-24.9 \mathrm{~kg} / \mathrm{m}^{2}$ in the non pregnant state [18]. Considering three categories of $\operatorname{BMI}\left(<18.5 \mathrm{~kg} / \mathrm{m}^{2}=\right.$ low, $18.5-24.9 \mathrm{~kg} / \mathrm{m}^{2}=$ normal and $>$ $25 \mathrm{~kg} / \mathrm{m}^{2}=$ high $)$ and three categories of parity (1,2 and $>$ 2 ) as the possible variables, there would be nine possible categories of women in the study. Therefore assuming that $85 \%$ of women would fit the standard curve with a normal deviate of $5 \%$, the minimum sample size required for each category was calculated to be 46 resulting in a total sample size of 414 [19]. In a study carried out in Kegalle the mean birth weight of Sinhalese babies born at term was reported to be 2.85 (sd 467g) [20]. Since a large majority of women who reside in the Galle district are Sinhalese, the population standard deviation in Galle can be assumed to be similar to that reported in Kegalle. Therefore, the minimum sample size required to estimate the mean birth weight with a normal deviate of $5 \%$ and an accuracy of $50 \mathrm{~g}$ in a population having a standard deviation of $500 \mathrm{~g}$, was calculated to be 384 [19]. It was decided to adopt the larger sample size of 414.

Pregnant women $(n=468)$ who presented for antenatal care at the Teaching Hospital, Mahamodara, Galle (THMG) during the period 1 August 2007 to 30 April 2008 with periods of gestation (POG) of $<22$ weeks and not having anaemia, hypertension, diabetes mellitus, cardiac disease, hydramnios or multiple pregnancy, had their POG confirmed by ultrasound scan if a dating scan had not been carried out earlier. Their age, parity, height and weight were documented. The earliest recorded weight during the current pregnancy was used to calculate the BMI. Women who developed anaemia, hypertension, diabetes mellitus, hydramnios, an abnormal lie or death in-utro during the pregnancy, and those who defaulted prenatal clinic visits and therefore had less than four longitudinal SFH measurements, were excluded from the study. This resulted in 52 women being excluded from the study, leaving 416 for analysis.
Two customised charts were obtained for each woman after incorporating each woman's basic information including parity, height and weight and entering Indian and African as ethnicity in the GROW computer software [17]. This enabled the downloading of one CSFH - In and one CSFH - Af chart respectively for each woman. Each woman was also provided with a printed out FHB chart and a $\mathrm{GA} \pm 2$ to $3 \mathrm{~cm}$ chart. All four charts were incorporated in to the patient held antenatal records which she carried with her until the delivery.

Having identified the fundus of the uterus, using a non elastic tape with the centimetre markings facing the maternal abdomen, the SFH was measured from the top of the uterine fundus to the top of the symphysis pubis along the longitudinal uterine axis at each antenatal clinic visit and plotted on all four SFH charts. The data were also recorded and kept confidentially in an ongoing computer data base.

The SFH measurements were carried out mainly by the first author $(n=1359)$ and if the first author was unavailable, by the on call senior house officer $(n=179)$ in an opportunistic manner during the routine prenatal follow up. At the time of SFH measurement the first author and the on call senior house officer were blind to the women's POG.

Duplicate SFH measurements were also obtained in 400 participants by other house officers who were blind to the POG. All the women had routine antenatal care and had their SFH measured at four weekly intervals, fortnightly and weekly intervals between 20 - 28, 28 - 36 and 37 - 41 weeks respectively and plotted on the CSFHIn chart, $\mathrm{CSFH}-\mathrm{Af}$ chart, FHB chart and the GA \pm 2 to 3 $\mathrm{cm}$ chart. If any SFH measurement was found to be outside the reference range in any of the non customised SFH charts in any woman at any time, she was reviewed by the second or third author and managed appropriately.

Serial SFH measurements were used to predict LBW in all the charts. If the last SFH measurement was less than the cut off value in any specific chart, it was considered as "test positive" for that particular chart, irrespective of the previous SFH measurements obtained for that particular patient. If the last SFH measurement was within the normal range in any specific chart, and both the two previous SFH measurements were was less than the cut off value in any specific chart, this was also considered as "test positive" for that particular chart. If the last SFH measurement was within the normal range in any specific chart, and only one previous SFH measurement was less than the cut off value in any specific chart, this was considered as "test negative" for that particular chart.

The gestational age at delivery and the birth weight were recorded. The sensitivity, specificity, positive predictive value (PPV), negative predictive value (NPV), likelihood ratio of a positive test and the likelihood ratio of a negative test in the detection of a LBW baby at term, 
were calculated and compared among the four SFH charts used in the current study.

\section{Results}

Of the 416 participants recruited for the study, 164 $(39.4 \%)$ were primigravidae, $76(18.9 \%)$ had low BMI and $71(17.7 \%)$ had high BMI (Tables 1 and 2). The SFH measurements taken by two observers were highly correlated and no significant inter observer variation was seen. (Reliability Coefficient Alpha $=0.9774$, p <0.0001). Of the 416 participants recruited for the study 15 (3.6\%) had preterm deliveries and only the balance 401 underwent further analyses. The 401 babies born at term (37 -42 weeks gestation) had a mean birth weight of $2990 \mathrm{~g}$ (95\% CI 2945 - 3035) (Table 1). No significant association was seen between maternal parity and birth weight of the baby (Table 3).

The maternal BMI at booking was positively correlated to the birth weight of the baby $\left(\mathrm{r}^{2}=0.016, p=\right.$ 0.012 on simple linear regression analysis and $\mathrm{r}^{2}=0.017, \beta$ $=0.119, p=0.02$ on logistic regression analysis combining the effects of parity and BMI). The mean BMI of the low, normal and high BMI groups were $17.2 \mathrm{~kg} / \mathrm{m}^{2}(95 \% \mathrm{CI}$ $17.0-17.4), 21.8 \mathrm{~kg} / \mathrm{m}^{2}$ (95\% CI $\left.21.6-22.0\right)$ and $27.6 \mathrm{~kg} /$ $\mathrm{m}^{2}(95 \%$ CI $27.1-28.1)$ respectively. The mean birth weight in the low BMI group (2861 g, 95\% CI 2783 - 2938) was significantly higher than the mean birth weight in the normal BMI group (3043 g, 95\% CI 2991 - 3094, $p<0.01$ ). However, only a non significant increase of approx. $50 \mathrm{~g}$ was noted between mean birth weight of the high BMI group and the normal BMI group (Table 4).

In almost all the participants in whom the final SFH value was below the cut-off point for any particular chart (and therefore considered as being a 'test positive' for detection of LBW), two or more previous serial SFH measurements were below the respective cut-off points for the particular chart. In the detection of a LBW at term, the CSFH - In chart had the best sensitivity, specificity, PPV, NPV, and the likelihood ratios of a positive test and a negative test. Of the two non customised charts the GA \pm 2 to $3 \mathrm{~cm}$ chart was better than the FHB chart, because although the FHB chart had a specificity of $100 \%$ it had zero sensitivity (Table 5).

Table 1. Basic characteristics of study population $(n=416)$

\begin{tabular}{|c|c|c|c|}
\hline & Range & Mean & $95 \%$ Confidence Interval \\
\hline Age - years & $16-45$ & 27.5 & $26.9-28.1$ \\
\hline Body mass index $-\mathrm{kg} / \mathrm{m}^{2}$ & $13.5-33.7$ & 21.8 & $21.5-22.2$ \\
\hline Period of gestation at delivery - days & $242-293$ & 275 & $273.3-276.5$ \\
\hline Birth weight of babies delivered at term $(n=401)$ & $1670-4450 g$ & $2990 \mathrm{~g}$ & $2945-3035 g$ \\
\hline Birth weight of babies delivered pre-term $(n=15)$ & $1630-2820 \mathrm{~g}$ & $2230 \mathrm{~g}$ & $2067-2393 g$ \\
\hline Parity : range & & $1-7$ & \\
\hline median $(\mathrm{IQR})$ & & $2(2)$ & \\
\hline Primigravidae $(\%)$ & & $164(39.4)$ & \\
\hline Pre-term deliveries $(\%)$ & & $15(3.6)$ & \\
\hline
\end{tabular}

$\mathrm{IQR}$ = inter quartile range

Table 2. Distribution of parity and body mass index $(n=401)$

\begin{tabular}{|c|c|c|c|c|}
\hline & $P 1$ & $P 2$ & $>P 2$ & Total \\
\hline $\mathrm{BMI}<18.5 \mathrm{~kg} / \mathrm{m}^{2}$ & 38 & 19 & 19 & $(18.9)$ \\
\hline BMI $18.5-24.9 \mathrm{~kg} / \mathrm{m}^{2}$ & 96 & 70 & 88 & $(63.3)$ \\
\hline $\mathrm{BMI}>25 \mathrm{~kg} / \mathrm{m}^{2}$ & 20 & 25 & 26 & $(17.7)$ \\
\hline Total & 154 & 114 & 133 & 401 \\
\hline
\end{tabular}

$\mathrm{BMI}=$ body mass index, $\mathrm{P}=$ ongoing pregnancy

Table 3. Association of parity and birth weight

\begin{tabular}{|c|c|c|c|c|c|}
\hline Parity & $\begin{array}{c}1 \\
(n=154)\end{array}$ & $\begin{array}{c}2 \\
(n=114)\end{array}$ & $\begin{array}{c}3 \\
(n=79)\end{array}$ & $\begin{aligned} & \geq 4 \\
(n & =54)\end{aligned}$ & $\begin{array}{c}\text { Total } \\
(n=401)\end{array}$ \\
\hline Birth weight $<2.5 \mathrm{~kg}$ & $\begin{array}{c}18 \\
(11.6 \%)\end{array}$ & $\begin{array}{c}13 \\
(11.4 \%)\end{array}$ & $\begin{array}{c}11 \\
(13.9 \%)\end{array}$ & $\begin{array}{c}6 \\
(11.1 \%)\end{array}$ & $\begin{array}{c}48 \\
(11.9 \%)\end{array}$ \\
\hline
\end{tabular}

Chi-square $=0.4, p=0.9, \mathrm{r}^{2}=0.004, p=0.2$ 
Table 4. Association of maternal body mass index and birth weight

\begin{tabular}{|c|c|c|c|c|}
\hline & & $\begin{array}{l}B M I<18.5 \mathrm{~kg} / \mathrm{m}^{2} \\
(n=76)\end{array}$ & $\begin{array}{l}\text { BMI } 18.5-24.9 \mathrm{~kg} / \mathrm{m}^{2} \\
(n=254)\end{array}$ & $\begin{array}{l}B M I>25 \mathrm{~kg} / \mathrm{m}^{2} \\
(n=71)\end{array}$ \\
\hline Range & & $14.1-18.4$ & $18.5-24.9$ & $25-33.7$ \\
\hline Mean & & 17.2 & 21.8 & 27.6 \\
\hline SD & & 0.9 & 1.7 & 2.2 \\
\hline $95 \% \mathrm{CI}$ & & $16.9-17.4$ & $21.6-22$ & $27.1-28.1$ \\
\hline \multicolumn{5}{|c|}{ Birth weight (g) } \\
\hline & Range & $2110-3570$ & $1850-4350$ & $1670-4450$ \\
\hline & Mean & $2861 *$ & $3043^{*}$ & 3094 \\
\hline & $\mathrm{SD}$ & 343 & 422 & 545 \\
\hline & $95 \% \mathrm{CI}$ & $2783.8-2938.2$ & $2991.1-3094.9$ & $2967.2-3220.8$ \\
\hline
\end{tabular}

Simple linear regression: $\mathrm{r}^{2}=0.016, p=0.012$

Logistic regression of BMI and parity vs birth weight:

$\mathrm{r}^{2}=0.017$, for parity $\beta=0.037, p=0.461$, and for BMI $\beta=0.119, p=0.019$

$*=p<0.01$

Table 5. Validity of Simphysio Fundal Height Charts in the detection and exclusion of a low birth weight $(<2.5 \mathrm{~kg})$ baby at term ( $>37$ weeks gestation) $(n=401)$

\begin{tabular}{|c|c|c|c|c|}
\hline & $C S F H-A f$ & $C S F H-I n$ & $G A \pm 2$ to $3 \mathrm{~cm}$ & $F H B$ \\
\hline Sensitivity & $\begin{array}{c}54.2 \% \\
(39.3-68.4)\end{array}$ & $\begin{array}{c}62.5 \% \\
(95 \% \mathrm{CI}: 48.5-74.7)\end{array}$ & $\begin{array}{c}81.2 \% \\
(95 \% \mathrm{CI}: 66.9-91.0)\end{array}$ & (95\%CI:0-9.2) \\
\hline Specificity & $\begin{array}{c}96.9 \% \\
(94.3-98.3)\end{array}$ & $\begin{array}{c}98.5 \% \\
(95 \% \mathrm{CI}: 96.4-99.5)\end{array}$ & $\begin{array}{c}86.9 \% \\
(95 \% \mathrm{CI}: 82.9-90.2)\end{array}$ & $\begin{array}{c}100 \% \\
(95 \% \mathrm{CI}: 98.6-100.0)\end{array}$ \\
\hline PPV & $\begin{array}{c}70.3 \% \\
(52.8-83.6)\end{array}$ & $\begin{array}{c}87.5 \% \\
(95 \% \text { CI:72.3 - 95.3) }\end{array}$ & $\begin{array}{c}45.8 \% \\
(95 \% \mathrm{CI}: 35.1-57.0)\end{array}$ & $\mathrm{NaN}$ \\
\hline NPV & $\begin{array}{c}93.4 \% \\
(90.8-96.1)\end{array}$ & $\begin{array}{c}94.2 \% \\
(95 \% \text { CI:91.2 - 96.3) }\end{array}$ & $\begin{array}{c}97.1 \% \\
(95 \% \mathrm{CI}: 94.77-98.6)\end{array}$ & $\begin{array}{c}88 \% \\
(95 \% \mathrm{CI}: 84.3-90.9)\end{array}$ \\
\hline LR Pos & $\begin{array}{c}17.4 \\
(9.5-32.9)\end{array}$ & $\begin{array}{c}43.1 \\
(95 \% \mathrm{CI}: 17.6-105.4)\end{array}$ & $\begin{array}{c}6.2 \\
(95 \% \mathrm{CI}: 4.6-8.4)\end{array}$ & $\mathrm{NaN}$ \\
\hline LR Neg & $\begin{array}{c}0.48 \\
(0.35-0.64)\end{array}$ & $\begin{array}{c}0.38 \\
(95 \% \mathrm{CI}: 0.27-0.53)\end{array}$ & $\begin{array}{c}0.21 \\
(95 \% \mathrm{CI}: 0.12-0.39)\end{array}$ & $\begin{array}{c}1 \\
(95 \% \mathrm{CI}: 1-1)\end{array}$ \\
\hline
\end{tabular}

$\mathrm{NaN}=$ calculation cannot be performed because the values entered include one or more instances of zero

$\mathrm{PPV}=$ positive predictive value

$\mathrm{NPV}=$ negative predictive value

LR Pos = likelihood ratio for a positive test

LR Neg = likelihood ratio for a negative test

\section{Discussion}

Of the customised charts the CSFH - In chart was better than the CSFH - Af chart in the detection and exclusion of a LBW baby at term in the study population. This could be explained by the fact that in comparison with Africans, Indians would be expected to be ethnically and genetically closer and similar to Lankans.

Although BMI and parity are both known to affect the birth weight of the baby, the influence of BMI on the birth weight of the baby has been shown to be more than that of parity [17,20-21]. In the current study, low BMI significantly affected the mean birth weight while no significant effect was noted with parity. Since no significant increase of mean birth weight was noted between the normal BMI group and the high BMI group, for convenience a SFH chart customised according to low $\left(<18.5 \mathrm{~kg} / \mathrm{m}^{2}\right)$ and normal $\left(18.5-24.9 \mathrm{~kg} / \mathrm{m}^{2}\right)$ could be developed for Sri Lanka. Until such a chart is developed, the mean BMI for these two groups $\left(17.2 \mathrm{~kg} / \mathrm{m}^{2}, 95 \% \mathrm{CI}\right.$ 17.0 - 17.4 and $21.8 \mathrm{~kg} / \mathrm{m}^{2}, 95 \%$ CI $21.6-22.0$ ) could be entered into the CSFH - In chart to generate one Reference Chart customised according to BMI (Figure 7). This could be easily incorporated in to the Maternal Pregnancy Record and be used by even family health workers in peripheral antenatal clinics. This chart would be similar to 
the growth chart used for monitoring a child's growth. The only difference would be that in the customised SFH chart the interpretation of the serial SFH measurements would depend on the maternal BMI at booking.

Ideally a customised SFH chart should be developed for Sri Lanka. Until such a chart is developed, in centres where computers and internet connectivity is available, the CSFH - In chart could be used for better monitoring of pregnant women with a view to improving the detection and exclusion of SGA fetuses and LBW babies at delivery. In the centres where computers and internet connectivity are not available, the $\mathrm{GA} \pm 2$ to $3 \mathrm{~cm}$ chart should be used in preference to the FHB chart.

A symphysio fundal height chart customised according to two groups, low and normal body mass index categories at booking, should be developed for Sri Lanka. Until this is developed, one Reference Chart customized according to BMI or the gestational age \pm 2 to $3 \mathrm{~cm}$ chart could be used. If computers and internet connectivity are available, the customized symphysio fundal height charts used for Indians in the UK may be used.

\section{References}

1. Coomaraswamy A, Fisk NM, Gee H, Robson SC. The investigation and management of the small for gestational age fetus. Green-top Guideline No. 31. Royal College of Obstetricians and Gynaecologists London, 2002.

2. Ott WJ. The diagnosis of altered fetal growth. Obstetrics and Gynaecology Clinics of North America 1998; 15: 237-63.

3. Mathai M, Jairaj P, Muthurathna S. Screening for light-for -gestational age infants: a comparison of three simple measurements. British Journal of Obstetrics and Gynaecology 1987; 94: 217-21

4. Persson B, Stangenberg M, Brodin LNO, Holmberg NG, Vaclavincova V. Prediction of size of infants at birth by measurement of symphysis fundus height. British Journal of Obstetrics and Gynaecology 1986; 93: 206-11.

5. Neilson JP. Symphysis - fundal height measurement in pregnancy. Cochrane Database Systematic Review 2000.

6. Arulkumaran S, Symonds IM, Fowlie A eds. Oxford Handbook of Obstetrics and Gynaecology. Oxford University Press, Oxford 2004, p7.

7. Chang TC, Robson SC, Boys RJ, Spencer JA. Prediction of the small for gestational age infant: which ultrasonic measurement is best? Obstetrics and Gynaecology 1992; 80: $1030-8$
8. Pearce JM, Campbell S. A comparison of symphysis - fundal height and ultrasound as screening tests for light-forgestational age infants. British Journal of Obstetrics and Gynaecology 1987; 94: 100-4

9. Steingrimsdottir T, Cnattingius S, Lindmark G. Symphysisfundus height: construction of a new Swedish reference curve, based on ultrasonically dated pregnancies. Acta Obstetricia et Gynecologica Scandinavica 1995; 74: 346-51.

10. Beazly JM, Underhill RA. Fallacy of the fundal height. British Medical Journal 1970; 4: 404-6.

11. Gardosi J, Chang A, Kalyan B, Sahota D, Symonds EM. Customised antenatal growth charts. Lancet 1992; 339: 283-7.

12. Mongelli M, Figueras F, Francis A, Gardosi J. A customised birthweight centile calculator developed for an Australian population. Australian and New Zealand Journal of Obstetrics and Gynaecology 2007; 47: 128-31.

13. McCowan L, Stewart AW, Francis A, Gardosi J. Acustomised birthweight centile calculator developed for a New Zealand population. Australian and New Zealand Journal of Obstetrics and Gynaecology 2004; 44: 428-31.

14. Gardosi J, Francis A. A customised standard to assess fetal growth in a US population. American Journal of Obstetrics and Gynaecology 2009; 23: e1-25.

15. Gardosi JO, Mongelli JM, Mull T. Intrauterine growth retardation. Baillieres Clinical Obstetrics and Gynaecology 1995; 9: 445-63.

16. Gardosi J, Francis A. Controlled trial of fundal height measurement plotted on customized antenatal growth charts. British Journal of Obstetrics and Gynaecology 1999; 106: 309-17.

17. Gardosi J Francis A. Customised Antenatal Growth Chart GROW - Chart v 7.5, 2007. Gestation Network. Available at http://www.gestation.netcom (accessed 01 August 2007 30 April 2008).

18. WHO Expert Consultation. Appropriate body mass index for Asian populations and its implications for policy and intervention studies. Lancet 2004; 363: 157-63.

19. World Health Organization. Teaching Health Statistics. Lesson and Seminar Outlines. 2nd Edn. Lwanga SK, Tye CY, Ayeny O. Eds. 1999; World Health Organization, Geneva. p77-8.

20. Nanayakkara CD. Anthropometric measurements of Sri Lankan newborns. Ceylon Journal of Medical Science 1998; 41: $1-5$

21. Ota E, Haruna M, Suzuki M, et al. Maternal body mass index and gestational weight gain and their association with prenatal outcomes in Vietnam. Bulletin of the World Health Organization 2011; 89: 127-36. 